\title{
Spine revisited: Principles and parlance redefined
}

\author{
M. V. L. Kothari, Lopa Mehta, M. Natarajan, V. M. Kothari ${ }^{\star}$ \\ Departments of Anatomy and *Medicine, Seth G.S. Medical College and KEM Hospital, Parel, Mumbai-400 012, India
}

\begin{abstract}
A revised appreciation of the evolution and the nature of bone in general and of vertebrae in particular, allows revisiting the human spine to usher in some new principles and more rational parlance, that embody spine's phylogeny, ontogeny, anatomy and physiology. Such an approach accords primacy to spine's soft-tissues, and relegates to its bones a secondary place.
\end{abstract}

Key Word: Eusemantics; intervertebral disc; noton; notus; pulvinot; spine; vertebra.

In phylogeny, and in ontogeny, the spine - as representing all the bones - arrives as a relaxed afterthought. So, if at all, it is the spine that should be attached to soft-tissues that spawned it.

Neurologists and neurosurgeons, in particular could appreciate that the mandibular nerve does NOT pass through the foramen ovale, but it is the foramen that secondarily gets fashioned round the preformed nerve.

Two decades of work ${ }^{[1]}$ in our department has allowed us to arrive at a Copernican change in vertebrate anatomy: From the head to the foot, the soft tissues form an uninterrupted ocean in which bones appear as islands of scleral inlay.

Appropriate technique applied to cadaveric parts allows you to deliver every bone out of its bed, with the ease of plucking a hair or pulling a pea out of its pod.

The human spine, including the cranium turns out to be a set of inlays in a bed of monolithic soft tissues of which the "intervertebral dise" forms an integral part. This generalization is applicable to all areas of the vertebrate body. One may safely generalize that no ligament/ tendon/muscle/ fascia is attached to any bone. The bone seems to be attached, an illusion laid bare as seen in the pictures here. It need not be emphasized that the limbs are evolutionary extensions of the spine, a fact concealed in thalidomide babies and limbless reptiles. So, what is true of spine is true of the limbs as well, and hence the pictorial data on shoulder and knee herein (Figures 1-4).
This singular conceptual and constructional reversal forms the panchreston that governs the entire locomotor system. Till today, right into the latest Gray's Anatomy, ${ }^{[2]}$ Rontgenian pictures and the cadavers have for too long given a prominence to bones they did not deserve. A time for a sea-change in our thinking has arrived. We are avoiding any further details on the spine. Spine and its synonym the vertebrae are terms that deserve to be radically changed.

Spine, derived ${ }^{[3,4,5]}$ from spike is rooted in Old English spica or spicing meaning a long nail, a thorn, sharp point or a splinter. Around the $14^{\text {th }}$ century, someone noticed the long spinous process of $\mathrm{C}_{7}$ and used this little part to name the whole cephalocaudally. The term spine has neither embryologic nor anatomic basis. At best, it is a convenient misnomer.

The terms vertebra, and hence vertebrate have had, a less unfortunate career. Derived from vertere meaning to turn, from Skt. Vartan ${ }^{[3,4,5]}$, it etymologically means a joint or to turn, and is akin to, verse, versatile, vortex and so on. The millipede is, in fact, the most vertebrate of all animals, endowed with thousands of joints, each of which verteres or turns. A Dictionary of Biology ${ }^{[6]}$ makes it clear that the cranium is more universal than the vertebral column, and suggests that the phylal term vertebrata could better be replaced by the term craniata.

Our authorship ${ }^{[7]}$ of an embryologic text that led us to the bony thought outlined earlier, has also allowed us to look at spine embryologically, and thus, without any intellectual dissonance, anatomically. The Gr. Root notos means the back, and hence the notochord from which the vertebral or more correctly the notonal column - comprising the discs, and a little later, the vertebrae - is derived. Each disc forms the central core of a body somite, and comprises the true segmental status be it the cord or the body. No wonder the spinal nerves emerge from the cord in line with the discs, and NOT the vertebrae as is usually implied. A disc, by definition is flat. The intevertebral disc is anything but that, the sacrolumbar disc being $2 \frac{1}{2}$ times taller in front than behind. A so-called disc, then is a $3 \mathrm{D}$ cushion that could be renamed as the pulvinot, from pulvinus- = cushion and notos = back. Each vertebra is, truly a ring, a bony annulus round the notonal (spinal) 


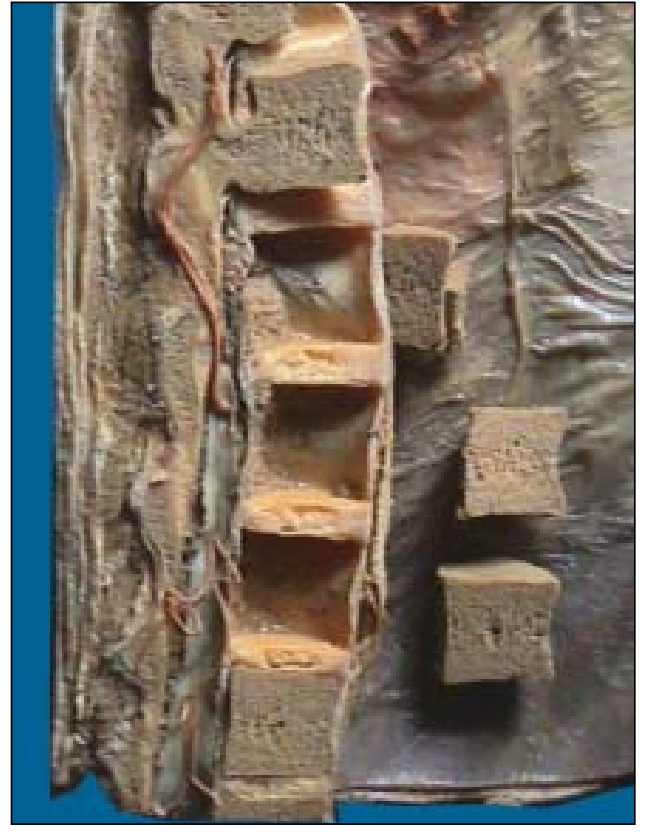

Figure 1: Some vertebral bodies have been delivered from their bed. The integrality of the intervertebral discs with the soft tissues is clear

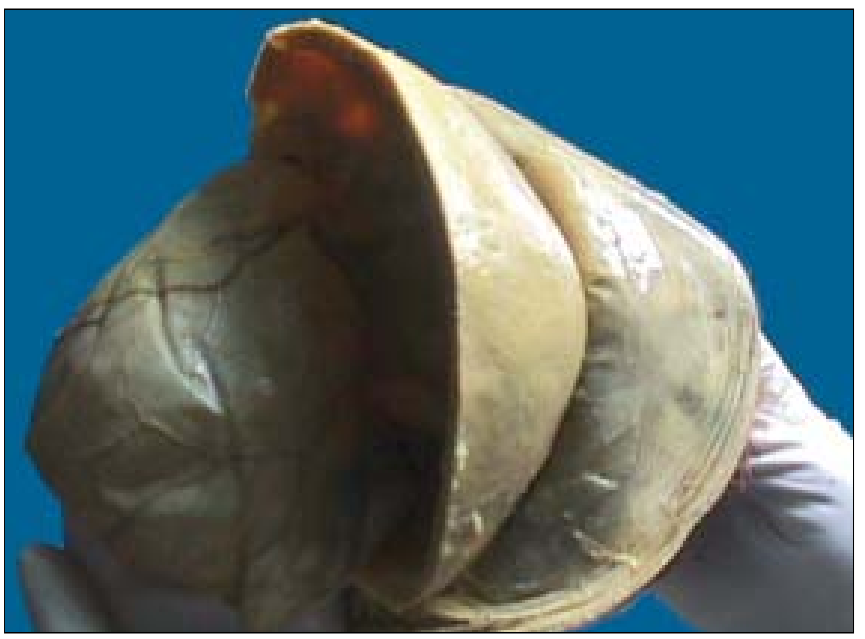

Figure 2: The dural and the scalp form the bed from which the latterly inlaid skull can be separated and lifted away with ease

cord. It thus merits the name notus (plural notuses, like lotuses) combining notos + annulus.

The human spinc/spinal column can be better rechristened as the noton / notonal column comprising the sequential pulvinots and the notuses. The suffix/prefix not in the foregoing will make every student or teacher hark back to embryology that is but verifiable as palpable adult anatomy. The detailed nomenclature of the parts of the pulvinots and notuses is due for publication. To those to whom the word spine is too dear to be jettisoned, recourse can be taken to acromymize ${ }^{[8]}$ SPINE to read as Sequiseqmental Pulvinotal Inlaid Ensemble/Extremitized, Ensemble, a verbal order

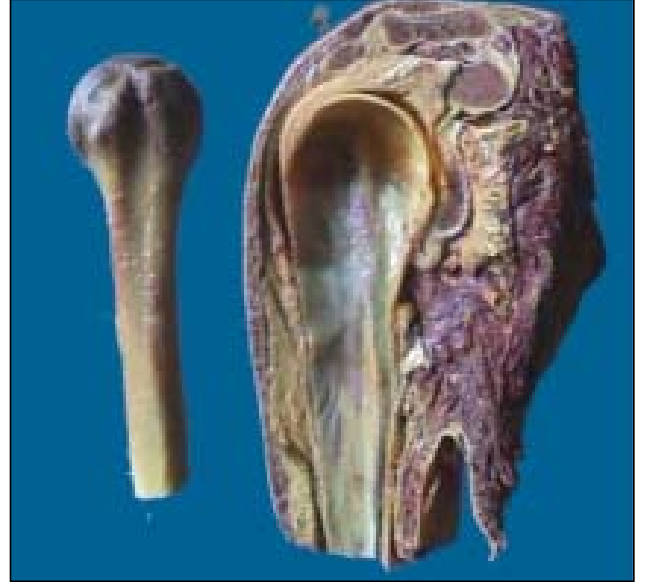

Figure 3: What is true of the spine and head applies to the shoulder as well

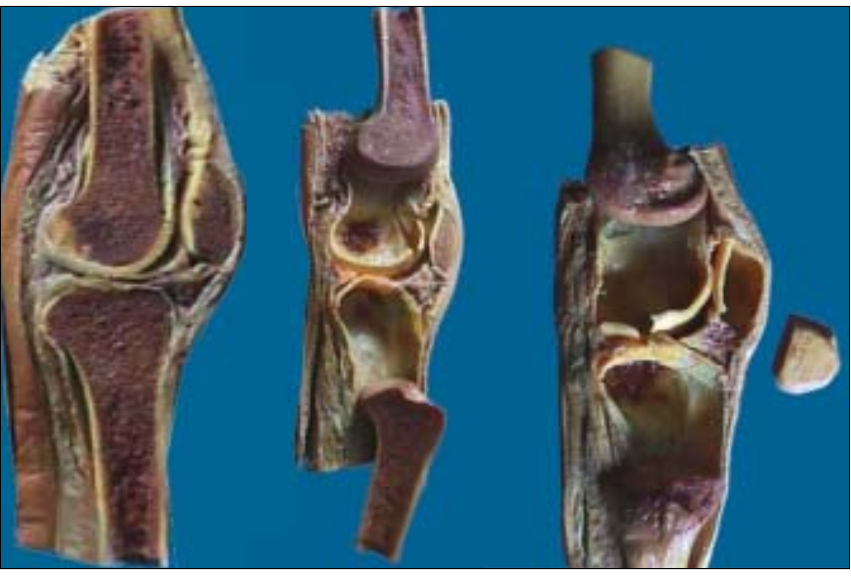

Figure 4: The specimen on the left clearly shows the lines of cleavage between the bones and their soft tissue beds. The bones can be lifted to illustrated the oceanic nature of soft tissues in which femur, tibia and patella are islands

pregnant with embryology, anatomy, physiology and eusemanties.

\section{References}

1. Kothari ML, Mehta Lopa, Natarajan M. Nature of bones and joints: A new perspective. J Postgrad Med 1990; 36:143-6

2. Grav's Anatomy The Anatomical Basis of Clinical Practise Ed, by Standring Susan, $39^{\text {th }}$ edition, Elsevier Churchill Livingstone, Edinburgh, London 2005.

3. Partridge E. Origins A short Etymological Dictionary of Modern English. Greenwich House, New York 1983.

4. Skinner HA. The Origin of Medical Terms, $2^{\text {nd }}$ Ed. William and Wilkins, Baltimore 1961.

5. Mehta Lopa, Natarajan M, Kothari MVL. Understanding Anatomical Terms : A Rapid Reader Companion to the Study of Anatomy, $2^{\text {nd }}$ Ed. Bhalani Publishing House, Mumbai 2004.

6. Abercrombie M, Hickman C.J, Johnson ML. A Dictionary of Biology, E.L.B.S. London 1970

7. Bhatnagar SM, Kothari ML, Mehta LA, Natarajan M. Essential of Human Embryology, $3^{\text {rl }}$ Ed. Orient Longman Pvt Ltd, Chennai 2000.

8. Natarajan M, Mehta Lopa, Kothari MVL. Acronymizing anatomy. Paper presented at $53^{\text {rd }}$ National Conference of Anatomical Society of India, $9^{\text {th }}$ January 2006. 